symptoms can follow the removal of post-menopausal ovaries.

The reproductive life in animals seems to continue, although becoming reduced, as the animal becomes older, and a post-menopausal period in women is a biological luxury of very recent origin.

Apart from the ageing of the ovary, the ageing of the individual ova must be considered. Two schools of thought exist here. The first believes that the ovary receives its quota of ova early in its life, and the other that new ova are constantly being destroyed and formed. This controversy has not yet been settled, although Prof. Krohn expressed some bias towards the former view.

Dr. Loraine directed attention to the fact that gonadotrophin titre in both the urine and the serum of menopausal and post-menopausal women is relatively high. It was shown by Heller and Shipley in 1951 that women who are less than twentyfive years beyond the menopause have a gonadotrophin excretion significantly higher than those in whom menopausal symptoms occur more than twenty-five years before the investigation. Menopausal gonadotrophin resembles in its biological properties the gonadotrophins excreted by men and by non-pregnant women. It has been generally assumed that menopausal urine contains entirely, or predominantly, follicle-stimulating hormone. Recent work in Edinburgh has, however, shown that this material is in addition a relatively rich source of a hormone stimulating interstitial cell activity.

Bioassay methods have indicated that although the amount of estrogen excreted by menopausal women is less than in those living a normal reproductive life, it is surprising that it still occurs at such a relatively high level considering that the menopause is a condition characterized by ovarian failure. Parkes in 1937 suggested that the adrenals might be the source of post-menopausal cestrogens. An accurate, sensitive and apparently specific chemical method by estimating separately œstriol, œstrone and œestradiol $17 \beta$ has now been developed in Edinburgh by Brown. Confirmation of the bioassay work has been obtained in preliminary experiments using these methods.

Two theories have been put forward to account for menopausal symptoms. The first is the theory of gonadotrophin excess, and the second the theory of œestrogen lack; but there is now a good deal of evidence that the former is not correct. Even though the cestrogen withdrawal theory seems more likely, there are still several objections to this, and it seems that neither of the hormonal theories explains the cause of menopausal symptoms.

Dr. Thung pointed out that the involutionary changes in the mouse ovary are similar to those in man, the most characteristic of these changes being the decrease in the number of follicles until, finally, only a few degenerative follicles are left; however, there are some changes which take place in the ageing mouse ovary which are very different from those found in the ageing human ovary.

This is due to fundamental differences in structure between the two types of ovary. The human ovary has a connective tissue core, the medulla, around which lies a relatively thin cortical portion which contains the follicles and corpora lutea. By comparison, the mouse ovary contains very little interstitial tissue and no medulla: it is little more than a cluster of follicles and corpora lutea. Also, the mouse ovary during its reproductive period (about one year) produces a much larger number of follicles, bouh mature and atretic, than the human ovary in a similar period. Moreover, each of these follicles is destined to a shorter existence. The human ovary in ageing becomes progressively more fibrotic, whereas in the mouse ovary very little fibrous scar tissue is formed - the cells of the degenerating follicles simply disintegrate and disappear. The pellicles surrounding the degenerating ova survive as crinkled remnants and often become calcified. In strains of mice susceptible to amyloid degeneration, more parenchyma is present in ageing ovaries; and hyaline infiltration may occur, particularly in the corpora lutea, which may afterwards also become calcified.

In ageing mouse ovaries, large phagocytic cells filled with lipo-fuscin pigment (ceroid) appear and increase in number with age.

These aged ovaries may still show some functional activity ; for example, an cestrous cycle persists in the vagina of the mouse (vaginal smear technique) long after the loss of fertility, and these have in some cases been observed to persist even up to the moment of dearh. This suggests that some part of the ovary continues to secrete may, in fact, be the germinal epithelium, which not only becomes more obvious but also seems to have a proliferative tendency in the old ovary, resulting in small ingrowing tubules and producing certain cell groups which look like small follicles without ova.

G. H. Bourne

\section{WINTER OBSERVATIONS ON A ZONE OF CLIMATIC MODIFICATION IN THE NORWEGIAN ARCTIC}

\author{
By N. C. NEGRI
}

Leader and Meteorologist, Lyngen Winter Survey Expedition

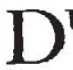

URING the post-war period of exploration, no less than seven scientific expeditions visited the Lyngen Peninsula, 250 miles beyond the arctic eircle on the north coast of Norway. However, all these parties confined their observations to the summer months; consequently there was no information relating to the prevailing winter conditions in the region. By the autumn of 1954 the need for such observations was such that the newly formed Mount Everest Trust Foundation agreed to sponsor a "comprehensive winter survey". The Royal Geographical Society approved the final plans, and supplied much of the necessary equipment.

This article summarizes the climatological observations made in a zone of modification at the head of a fjord on the north-west coast of the peninsula. The inner reaches of this fjord were separated from the main valley by two spits and an island. For the purposes of comparison, the expedition established a full-scale meteorological station half a mile north of these spits.

The mountain basin south of the spits clearly had an unusual local climate, for we observed the salt water within it freezing, although the temperature at the station was above $29^{\circ} \mathrm{F}$. After a brief investigation of the general conditions in the basin, we reached the conclusion that the cause of the phenomena was a cold air stream from the south. This 
much was obvious; but the task of locating the source of this air stream was a complex problem, with the normal difficulties of field-research increased by the extreme conditions of the locality, and the limited daylight. We decided that the only certain method of fixing the position of the source would be by establishing the relative situation of the lowest temperature in the basin at sea-level, and tracing the source from there. We accomplished this by circumnavigating the basin, measuring the temperature at frequent intervals. Eventually we succeeded in compiling sufficient reliable figures to plot isotherrns for the region. Simultaneously with these journeys, we ascended the slopes of the mountains rising from the basin, in order to determine the vertical extent of the climatic zone. The inversions recorded on all occasions showed the temperature at $1,000 \mathrm{ft}$. to be $10^{\circ} \mathrm{F}$. higher than that at sea-level. The curve of this temperature gradient indicated that the rise took place mainly in the upper $500 \mathrm{ft}$.

All the temperature-recording journeys proved beyond doubt that the very lowest temperatures occurred at a point just south of the fjord-ice at the base of a wide defile leading to a glacier-filled $\mathrm{cwm}$, at an altitude of $1,500 \mathrm{ft}$. As the mountain walls on either side of the defile reached heights exceeding $2,000 \mathrm{ft}$., it was safe to assume that the glacier cwm and the defile itself were both free from wind, and therefore unlikely to be affected by cold air currents from the interior of the peninsula. It followed from this that the source of the cold air stream was the glacier.

The sequence of events from the time that a parcel of cold air accumulates near the snout of the glacier can now be traced. By virtue of its greater density, the glacier-cooled air would push itself under any comparatively warm air in the vicinity, and flow down the subsidiary valley formed by the rock walls of the defile. On reaching sea-level, it would attain a state of almost complete stability, that is to say, there would be little or no convection within the air itself, or heat exchange between the snow cover of the basin and the air. In relation to the latter, it should be remembered that, for a climatologist working during the Aretic night, the polar nocturnal constant relieves him of problems of solar or terrestrial radiation.

Having reached the valley floor, the parcel of air would flow over the surface of the fjord-ice toward the open water in the north. As it approached the warmer air near the water, it would cease to be a level stratum, and become instead a wedge of air, behaving in exactly the same manner as a macroclimatic cold front. The water in the fjord was always $20^{\circ} \mathrm{F}$. warmer than the air from the south, and therefore a fog layer 5 metres thick and 3 metres above the surface of the water would form at the point of occlusion.

Our conclusion from the above was that, during winter months when the moderating factors of radiation and reflexion were set at nought by the absence of the sun, the local climate of the mountain basin was entirely dependent upon the glacier at the southern extremity of the fjord valley; also, that this modification of macroclimate was quite out of proportion to the relatively small area occupied by the glacier.

The significance of such an area is obvious when one considers the difficulties of studying the relationship between glaciers and climate in the lower latitudes of Europe, where the climatologist has to account for an extremely wide diurnal temperaturerange and other complicating agents, such as noc- turnal heat exchange, ablation of the snow, and erratic winds. All these disturbing influences are removed during the period after the winter solstice, and it is possible to obtain almost perfect continuity in climatic observations until the return of the sun in February. So it may be said that, in the glaciated areas of Arctic Scandinavia, the climatologist has a virgin field, easily accessible, and abounding in possibilities for winter research on a smaller, and consequently more accurate, scale than is at present possible in Austria or Switzerland.

\section{AUTOMATION IN THE SOVIET UNION}

71

HE U.S.S.R. claims to have achieved the automatic factory, but little detail is available; more definite information, at least indicating some of the lines along which research in this field is proceeding or is contemplated in the Soviet Union, may possibly be found in reports of two recent conferences : one on the modern theory of machines, and the other on the progress of automation in the consumer goods industries-mainly food and textiles.

The first of these, reported in Vestnik Akad. Nauk SSSR, No. 12, 1954, is by I. I. Artobolevskii and co-workers, and is chiefly devoted to the paper they themselves read at the conference, with a few brief notes on some of the other papers. The meeting was organized by the Institute of Machine Construction (affiliated to the Academy of Sciences of the U.S.S.R.), and was an attempt to strengthen the scientific foundations of the machine construction industry.

Artobolevskii's paper emphasizes the importance of the theory of machines and mechanisms, especially in relation to the growing demands of automation. Discussing first of all the general theory, he thinks this is fully developed only in the case of prime movers, and as yet very imperfectly in other directions. A main factor to-day is the greatly increased speed of operation and general efficiency, the effect of which still requires close study. But the most important direction for the development of modern machine design is that of automatizing and mechanizing technological or industrial operations. In recent years in the Soviet Union many types of automatic machine have been evolved. Automatic and continuous production lines have been widely adopted. Most of the heavy and laborious operations in mining, metallurgical, building and other industries have been mechanized. Soviet scientists have discussed many fundamental questions relating to automatic machines and mechanisms. More especially they have outlined the general theory of the cyclogram automatics, analysed problems of regulation and control, suggested means and methods for design of individual types of mechanisms, and so forth.

Many difficulties in the theory of automatic machines still await discussion and solution. Among the fundamentals, for example, are the dynamics of free-flowing bodies or material to be mechanically ground, screened and conveyed; the dynamics of bending or flexing of fibres and threads in textile, cable-making and similar machines; the hydrodynamics of viscous liquids to be treated in separators, centrifugal or other; the aerodynamics of air currents in wind motors and the like, including the various kinds of pneumatic mechanisms. These 